\title{
Effects of geometries on flow characteristics and reforming performance of a steam-methane reformer
}

\author{
J. S. Lee ${ }^{1}$, J. Seo ${ }^{1}$, H. Y. Kim ${ }^{1}$, S. Park ${ }^{1}$ and Y. Lee ${ }^{2}$ \\ ${ }^{1}$ School of Mechanical Engineering \\ Korea University \\ 5-Ga, Anam-dong, Sungbuk-gu, Seoul, 136-701 (Korea) \\ Fax number:+82 23290 3752, e-mail: nti9337@korea.ac.kr, ichloveu@korea.ac.kr, kimhy@korea.ac.kr, \\ spark@korea.ac.kr \\ ${ }^{2}$ Energy Efficiency Research Centre \\ Korea Institute of Energy Research \\ 71-2, Jang-dong, Yusong-gu, Taejon, 305-343 (Korea) \\ Fax number:+82 42860 3334, e-mail: yjl@kier.re.kr
}

\begin{abstract}
The effects of geometries on flow characteristics and reforming performance were studied in a $250-\mathrm{kW}$ fuel cell reformer. A reformer system was numerically simulated using a simplified three-dimensional model domain with an appropriate user-defined function. The numerical results were compared with experimental data for validation. Outlet position was selected as a parameter for investigating the effects of geometry variation. The reference case has outlet at the bottom of the combustion furnace, and the outlet positions were changed from bottom to top. The numerical results show that the flow characteristics are quite different when the outlet position is changed. And the flow characteristics in the combustion furnace strongly affect the outlet temperature of reformer and reforming performance. Overall, flows of the corner sides were dominant, and the reformers which are located around the corner sides have relatively higher outlet temperatures and better reformer performances. Overall reformer performance and the flows in the combustion furnace can be predicted by measuring the outlet temperatures of reformer tubes. The effects of outlet position on the reformer performance are relatively lower than on the outlet temperatures of reformers.
\end{abstract}

\section{Key words}

geometry parameter, outlet position, fuel cell, reformer

\section{Introduction}

With the growing world population and energy demand, it is clear that fossil fuels must be offset by sustainable, clean energy sources. Fuel cells are one of the most promising alternatives among new renewable energy sources, especially in the power generation field. For power generation or large-building applications, the Molten Carbonate Fuel Cell (MCFC) and the Solid Oxide Fuel Cell (SOFC) are most often used. MCFC and SOFC consume syngas, which is comprised of hydrogen and carbon monoxide, as fuel. Because syngas is produced in the reforming process, in which hydrocarbon fuels are converted to hydrogen and carbon monoxide, it is important to understand this process as well as the heat transfer process in the reformer, for the design an optimal fuel-cell system. Because the reforming process involves complex chemical reactions, flow and reforming characteristics are difficult to measure experimentally. Computational modelling of the reforming process is also challenging because the reforming process includes both complex combustion and reforming reactions, which must be modelled simultaneously.

Steam reforming is the most common method for producing hydrogen in the chemical process industry. The primary steam reforming reaction is strongly endothermic, and reactor designs are typically limited by heat transfer rather than reaction kinetics [1]. Several numerical approaches have investigated steam reformers about geometric parameters [2-6]. Pedenera et al. [2] examined the effects of reforming tube diameter and catalyst activity distribution on reformer performance. De Jong et al. [3] evaluated the effects of design modifications on the performance of the reformer. Murty and Murthy [4] investigated the influence of various parameters, such as the steam-to-carbon ratio, system pressures, inlet tube temperatures, flame length, and reformer size, on reformer performance. Shayegan et al. [5] simulated a steam reformer with a low Reynolds number, large tube diameter, and no extra steam in the feed. Brus and Szmyd [6] used a radiative model to simulate the heat transfer from the furnace to the reactor; they examined the effects of the reformer position in the module chamber and the emissivity of the reformer surfaces on the temperature and methane conversion characteristics of the reformer. 
Researchers have primarily examined the reformer system, neglecting the fact that the system really includes both reforming and combustion reactions. They typically considered parameters such as steam-to-carbon ratio, flow rate in the reforming tube, size and shape of the reformer, temperature and pressure at the tube inlet, and so on. Almost universally, they used heat transfer empiricisms without solving rate equations of combustion reactions. This work focuses on the effects of geometries on flow characteristics and reformer performance by simultaneous modelling the reforming reactor and the combustion furnace accounting for reaction kinetics. For an industrial steam reformer, position of outlet of the combustion furnace was varied from bottom to top. The kinetics of the steam-methane reaction outlined by $\mathrm{Xu}$ and Froment [7] was used to represent the reforming reaction, while an eddy-dissipation model was used to simulate the combustion reaction in the furnace [8]. Both reaction kinetics were built into the model with user-defined functions. The results of this work provide insights into the position of outlets within the combustion furnace of a reformer, specifically 250-kW MCFC and SOFC fuel cells. The steam reformer is simulated as a three-dimensional system, and the simulation results are compared with experimental data for validation. Then, the effects of outlet positions on the reformer system are simulated and discussed. The overall results are summarized as plots of temperatures, mole fractions of the species along the reactor or at the reactor outlet, and contours of some parameters used to evaluate the reformer performance.

\section{Object of the study}

As shown in Fig. 1, a mixture of steam and methane gas passes through the reactor filled with a nickel-based catalyst where the mixture is reformed by the heat supplied by the combustion furnace surrounding the reactor. Table I presents the experimental specifications including operating conditions and catalyst properties. Mass-flow controllers quantified the flow rates of methane and air. Water was delivered by a pump. For the reforming reaction, methane gas and water vapour were mixed and preheated through the heat exchanger, and then supplied to the catalyst via an inlet header. Reformate gas was gather via an outlet header and sent to a stack of fuel cell or gas

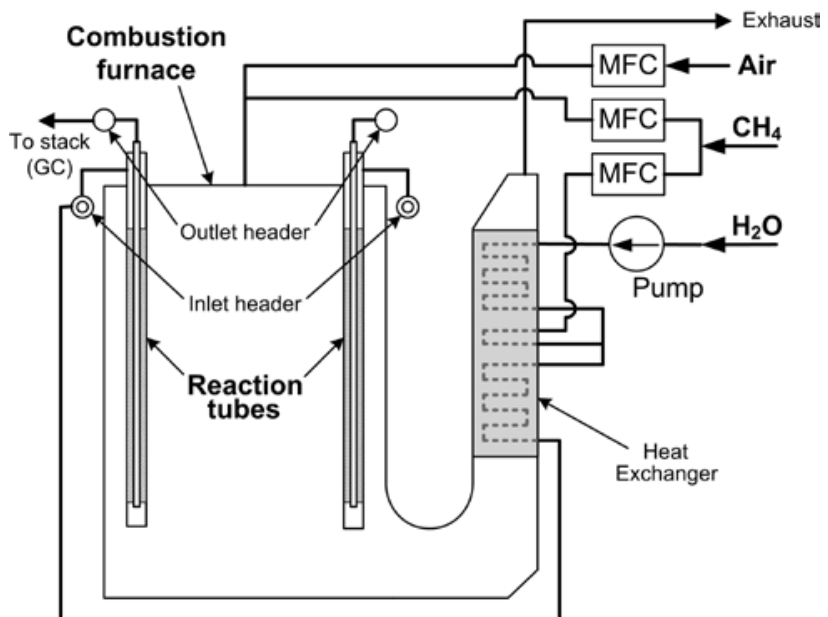

Fig. 1. Schematic of the experimental apparatus of the reformer for $250 \mathrm{~kW}$ fuel cell.
Table I. - Specifications of the experiment of the reformer for $250 \mathrm{~kW}$ fuel cell

\begin{tabular}{|l|l|}
\hline \multicolumn{2}{|l|}{ Dimensions } \\
\hline Height of the furnace $(\mathrm{m})$ & 3.2 \\
\hline Width of the furnace $(\mathrm{m})$ & 2.1 \\
\hline Height of the catalyst zone (m) & 2.0 \\
\hline Volume of the catalyst zone (liter/EA) & 0.139 \\
\hline Number of the reactor(EA) & 24 \\
\hline Operating conditions & 4 \\
\hline Operating pressure (atm) & 500 \\
\hline Inlet temperature of reformer $\left({ }^{\circ} \mathrm{C}\right)$ & 60 \\
\hline Flow rate of fuel to reactor $\left(\mathrm{Nm}^{3} / \mathrm{h}\right)$ & 82 \\
\hline Flow rate of fuel to combustor $\left(\mathrm{Nm}^{3} / \mathrm{h}\right)$ & 82 \\
\hline Catalyst properties & $>12$ \\
\hline Ni, Total(Wt\%) & 7 hole \\
\hline Shape & 16 \\
\hline Outer diameter (mm) & 11 \\
\hline Height (mm) & 3.4 \\
\hline Hole diameter (mm) & 7 \\
\hline Number of holes (EA) &
\end{tabular}

chromatograph for measurement of its composition. For the combustion reaction, methane gas and air were supplied to the top of the furnace. Fuel/air mixture reacts in the combustion furnace and supply heat to the reaction tubes and heat exchanger.

\section{Model description}

A CFD simulation was conducted using the commercial code Fluent ${ }^{\mathrm{TM}}$ version 6.3.26 [9] with an appropriate user-defined function to simulate the reforming and combustion reactions. The reformer was simplified by applying symmetry, and removing the headers and heat exchanger. The calculation domain shown in Fig. 2 is a simplified version of the complex 3-D configuration. Calculations with the three-dimensional configuration were performed by a double-precision, pressure-based solver at the steady state condition.

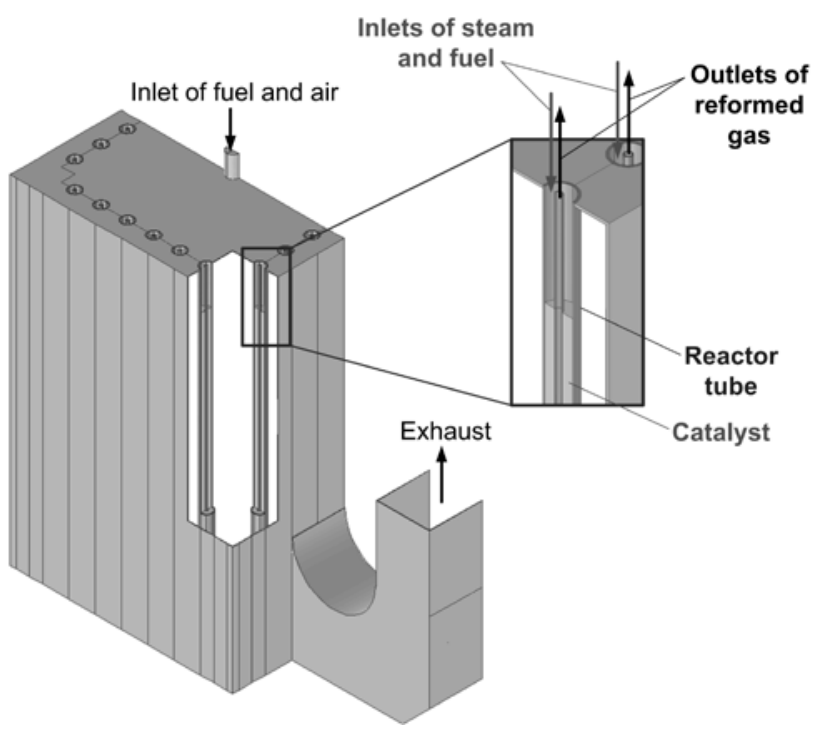

Fig. 2. Sliced and magnified view of the simplified calculation domain of reformer for $250 \mathrm{~kW}$ fuel cell.

\section{A. Governing equations}


The 3-D governing equations of conservation of mass, momentum, energy, and species for the gas phase are given as follows:

$$
\begin{gathered}
\nabla \cdot(\rho \vec{v})=0 \\
\nabla \cdot(\rho \overrightarrow{v v})=-\nabla p+\nabla \cdot(\vec{\tau})+\vec{F} \\
\nabla \cdot(\vec{v}(\rho E+p))=\nabla \cdot\left(\lambda_{\text {eff }} \nabla T-\sum h_{j} \vec{J}_{j}\right)+S_{h} \\
\nabla \cdot\left(\overrightarrow{\rho v Y_{i}}\right)=-\nabla \cdot \vec{J}_{i}+R_{i}
\end{gathered}
$$

where the stress tensor $\bar{\tau}$ is defined as

$$
\bar{\tau}=\mu\left[(\overrightarrow{\nabla v}+\overrightarrow{\nabla v})-\frac{2}{3} \nabla \cdot \overrightarrow{v I}\right]
$$

and the energy $E$ is $E=h-\frac{p}{\rho}+\frac{v^{2}}{2}$.

The momentum source terms, $\vec{F}$, stand for the gravitational body forces and the external body forces of porous-media. The energy source term, $S_{h}$, is comprised of the chemical reaction heat, radiation, and the heat sinks. The species source term, $R_{i}$, represents the net rate of production of species $i$ by the chemical reaction.

The RNG $k-\varepsilon$ model was adopted for turbulence calculations, and the Discrete Ordinates model was adopted for radiation calculation.

\section{B. Properties of the single species and gas mixture}

Because the heat/mass transfer and reaction phenomena in the system are strongly affected by the properties of the gas components, these properties need to be defined for numerical simulations. The specific heat of the single species is obtained from piecewise-polynomial functions of temperature. Thermal conductivities and viscosities of the single species are based on the information in the NIST Chemistry WebBook [10] at $1 \mathrm{~atm}$ and the mean operating temperature of this system, assumed to be $1100 \mathrm{~K}$. The specific heat of the gas mixture is calculated as a massfraction average of the heat capacities of the pure species:

$$
c_{p, \operatorname{mix}}=\sum_{i} Y_{i} c_{p, i} \text {. }
$$

The density of the gas mixture is calculated by the ideal gas mixing law:

$$
\rho_{\text {mix }}=\frac{p_{o p} M_{W, \text { mix }}}{R T} .
$$

The thermal conductivity and viscosity of the gas mixture are calculated based on kinetic theory as:

$$
\lambda_{\text {mix }}=\sum_{i} \frac{X_{i} \lambda_{i}}{\sum_{j} X_{j} \varphi_{i j}}
$$

and

$$
\mu_{\text {mix }}=\sum_{i} \frac{X_{i} \mu_{i}}{\sum_{j} X_{j} \varphi_{i j}}
$$

where

$$
\varphi_{i j}=\left[1+\left(\frac{\mu_{i}}{\mu_{j}}\right)^{1 / 2}\left(\frac{M_{W, j}}{M_{W, i}}\right)^{1 / 4}\right]^{2} /\left[8\left(1+\frac{M_{W, i}}{M_{W, j}}\right)\right]^{1 / 2}
$$

Maxwell-Stefan equations are used to obtain the diffusive mass flux of a multi-component system. Assuming ideal gas behaviour, and negligible pressure and thermal diffusions, the diffusive mass flux vector can be calculated as:

$$
\begin{gathered}
\vec{J}_{i}=-\sum_{j=1}^{N-1} \rho D_{i j} \nabla Y_{j}, \\
D_{i j}=[D]=[A]^{-1}[B], \\
A_{i i}=-\left(\frac{X_{i}}{\mathcal{D}_{i N}} \frac{M_{W}}{M_{W, N}}+\sum_{\substack{j=1 \\
j \neq i}}^{N} \frac{X_{j}}{\mathcal{D}_{i j}} \frac{M_{W}}{M_{W, i}}\right), \\
A_{i j}=X_{i}\left(\frac{1}{\mathcal{D}_{i j}} \frac{M_{W}}{M_{W, j}}-\frac{1}{\mathcal{D}_{i N}} \frac{M_{W}}{M_{W, N}}\right), \\
B_{i i}=-\left(X_{i} \frac{M_{W}}{M_{W, N}}+\left(1-X_{i}\right) \frac{M_{W}}{M_{W, i}}\right), \\
B_{i j}=X_{i}\left(\frac{M_{W}}{M_{W, j}}-\frac{M_{W}}{M_{W, N}}\right)
\end{gathered}
$$

where [A] and [B] are $(N-1) \times(N-1)$ matrices and [D] is an $(N-1) \times(N-1)$ matrix of the generalized Fick's law diffusion coefficients $D_{i j}$. Binary mass diffusion coefficients are taken from the literature of Roses et al. [11].

The Weighted-Sum-of-Gray-Gases Model (WSGGM) is used to define the composition-dependent absorption coefficients. This model is useful for simulation of radiation in combustion applications. WSGGM estimates the absorption coefficient and the total emissivity over the distance $s$ as:

$$
\alpha=-\frac{1}{s} \ln (1-\varepsilon), \quad \varepsilon=\sum_{i=0}^{I} a_{\varepsilon, i}(T)\left(1-e^{-\kappa p s}\right),
$$

where $a_{\varepsilon, i}$ are the emissivity weighting factors for the $i$ th fictitious gray gas, $\kappa_{i}$ is the absorption coefficient of the $i$ th gray gas, and $p$ is the sum of the partial pressures of all absorbing gases. The coefficients $a_{\varepsilon, i}$ and $\kappa_{i}$ are specified with Fluent default values [9].

\section{Properties of the solid materials}

The components used in the experiments were made from alloy steels and catalyst. Solid properties were taken from various materials. Properties of tube (HK40) were taken from a data sheet on a website [12]. Properties of pipe (Alloy $800 \mathrm{H}$ ) were taken from a data sheet on another website [13]. Catalyst is composed of $\mathrm{Mg}\left(\mathrm{Al}_{2} \mathrm{O}_{2}\right)_{2}$ and Nickel. Weight percentage was given by the manufacturer. Density, specific heat, and thermal conductivity of $\mathrm{Mg}\left(\mathrm{Al}_{2} \mathrm{O}_{2}\right)_{2}$ and Nickel were taken from an online material data base: MatWeb [14]. 


\section{Reforming reaction}

The steam-methane reforming reaction occurs on the nickel-based catalyst. The kinetic model of $\mathrm{Xu}$ and Froment [7] was supplied to the code as a user-defined function for the simulation of the reaction process. Three global reaction schemes are expressed as follows:

Reaction I: $\mathrm{CH}_{4}+\mathrm{H}_{2} \mathrm{O} \rightarrow \mathrm{CO}+3 \mathrm{H}_{2}$

Reaction II: $\mathrm{CO}+\mathrm{H}_{2} \mathrm{O} \rightarrow \mathrm{CO}_{2}+\mathrm{H}_{2}$

Reaction III: $\mathrm{CH}_{4}+2 \mathrm{H}_{2} \mathrm{O} \rightarrow \mathrm{CO}_{2}+4 \mathrm{H}_{2}$

Their respective rate equations are:

For Reaction I:

$$
\eta_{1} r_{1}=\frac{k_{1}}{p_{\mathrm{H}_{2}}^{2.5}}\left(p_{\mathrm{CH}_{4}} p_{\mathrm{H}_{2} \mathrm{O}}-\frac{p_{\mathrm{H}_{2}}^{3} p_{\mathrm{CO}}}{K_{1}}\right) /(\mathrm{DEN})^{2}
$$

For Reaction II:

$$
\eta_{2} r_{2}=\frac{k_{2}}{p_{\mathrm{H}_{2}}}\left(p_{\mathrm{CO}} p_{\mathrm{H}_{2} \mathrm{O}}-\frac{p_{\mathrm{H}_{2}} p_{\mathrm{CO}_{2}}}{K_{2}}\right) /(\mathrm{DEN})^{2}
$$

For Reaction III:

$$
\begin{aligned}
\eta_{3} r_{3}= & \frac{k_{3}}{p_{\mathrm{H}_{2}}^{3.5}}\left(p_{\mathrm{CH}_{4}} p_{\mathrm{H}_{2} \mathrm{O}}^{2}-\frac{p_{\mathrm{H}_{2}}^{4} p_{\mathrm{CO}_{2}}}{K_{3}}\right) /(\mathrm{DEN})^{2} \\
\mathrm{DEN} & =1+K_{\mathrm{CO}} p_{\mathrm{CO}}+K_{\mathrm{H}_{2}} p_{\mathrm{H}_{2}} \\
& +K_{\mathrm{CH}_{4}} p_{\mathrm{CH}_{4}}+K_{\mathrm{H}_{2} \mathrm{O}} p_{\mathrm{H}_{2} \mathrm{O}} / p_{\mathrm{H}_{2}}
\end{aligned}
$$

Rate coefficients and equilibrium constants are obtained from the Arrhenius equation and van't Hoff equation as:

$$
k_{i}=A\left(k_{i}\right) \exp \left(-\frac{E_{a, i}}{R T}\right), K_{j}=A\left(K_{j}\right) \exp \left(-\frac{\Delta H_{j}}{R T}\right)
$$

Considering the packed bed catalyst as a porous medium, the effectiveness factors are adopted in the rate equations taking into account the diffusional limitations of heat and mass transfer [15]. From the comparisons of the experimental data with the numerical results, the effectiveness factor for steam-methane reforming reactions was $\eta_{1}=0.001$, and that for the water-gas shift reaction was $\eta_{2}=0.1$. The pressure drop through the porous medium was modelled by adding a source term that represented a momentum sink to the standard fluid flow equations. The momentum sink is calculated by Ergun's equation:

$$
\frac{|\Delta p|}{L}=\frac{150 \mu}{D_{p}^{2}} \frac{\left(1-\varepsilon_{v}\right)^{2}}{\varepsilon_{v}^{3}} v_{\infty}+\frac{1.75 \rho}{D_{p}} \frac{\left(1-\varepsilon_{v}\right)}{\varepsilon_{v}^{3}} v_{\infty}^{2}
$$

where $\varepsilon_{v}$ is the void fraction (porosity), $D_{p}$ is the mean particle diameter, and $\mathrm{L}$ is the bed depth.

The effective thermal conductivity, $\lambda_{\text {eff }}$, of the porous medium is computed as the volume average of the fluid conductivity and the solid conductivity:

$$
\lambda_{\text {eff }}=\varepsilon_{v} \lambda_{f}+\left(1-\varepsilon_{v}\right) \lambda_{s}
$$

where $\lambda_{f}$ and $\lambda_{s}$ are the thermal conductivities of the fluid phase and the solid medium, respectively. Table 3 summarizes the parameters that were used to simulate the reforming reaction.

\section{E. Combustion reaction}

In non-premixed flames, turbulence slowly convects and mixes the fuel and oxidizer into the reaction zones where they burn quickly. In this study, a turbulence-chemistry interaction model, called the Eddy-Dissipation Model, was used to simulate the combustion reaction. Methane combustion reaction is expressed as follows:

$\mathrm{CH}_{4}+2 \mathrm{O}_{2} \rightarrow \mathrm{CO}_{2}+2 \mathrm{H}_{2} \mathrm{O}$ (Methane Combustion)

The net rate of production of species $i$ due to the combustion reaction, $R_{i, \text { comb. }}$, is given by the smaller value of the following two expressions:

$$
\begin{aligned}
& R_{i, \text { comb. }}=v_{i, \text { comb. }}^{\prime} M_{W, i} \alpha \rho \frac{\varepsilon_{d}}{k} \min _{R}\left(\frac{Y_{R}}{v_{R}^{\prime} M_{W, R}}\right) \\
& R_{i, \text { comb. }}=v_{i, \text { comb. }}^{\prime} M_{W, i} \alpha \beta \rho \frac{\varepsilon_{d}}{k} \frac{\sum_{P} Y_{P}}{\sum_{j}^{N} v_{j}^{\prime \prime} M_{W, j}}
\end{aligned}
$$

where $\alpha$ and $\beta$ are empirical constants equal to 4.0, and $0.5, Y_{P}$ and $Y_{R}$ are the mass fractions of any product species, $P$, and a particular reactant, $R$, respectively.

\section{F. Numerical method}

The governing equations were discretized using a control-volume-based technique. The SIMPLE algorithm was applied to enforce mass conservation and to obtain the pressure field. The second-order upwind scheme for calculating convective flux and the central-differencing scheme for calculating diffusive fluxes were used at the control volume surface. No-slip condition and zero temperature and species-concentration gradients were specified at the wall boundaries. Wall boundaries were treated as opaque walls for calculating radiation.

\section{Results and discussions}

\section{A. Model validation}

Prior to simulating the reformer system for various operating conditions, the numerical model with userdefined functions was first validated by simulating the system under the same operating conditions as the experiment. The reformate gas composition of the numerical model were compared to the experimental results. The model with the user-defined functions yielded errors of less than $5 \%$ for all species concentrations. Overall, the simulation showed good agreement with the experimental data, so the code was considered appropriate for other analyses of the reformer system.

\section{B. Effects of outlet position}

Fig. 3 shows that pathlines release from combustor inlets in each calculation domain. The pathlines were drawn for 8.0 seconds. As shown in the Fig. 3, supplied fuel/air mixture goes down to the bottom of the combustion furnace and then spreads to the side wall of the furnace. This flow is relatively uniform and it is shown in all cases. However, the flow from the side wall of the furnace is shown quite differently. Fig. 3 (a), (b) and (c) are represent the Case G1 (Reference case), Case G2 and 
Case G3, respectively. In the Fig. 3 (a) and (b), it is shown that three pathlines exit at the outlet of the combustor, but in the Fig. 3 (c), there was no pathline which exits at the outlet of the combustor in 8 seconds. In addition, exit time of the pathlines of Case G1 is shorter than that that of Case G2. It indicates that the flow residence time of Case G3 is largest.

In general, it is shown that the flow from the side wall is driven to the corners of the furnace. In particular, flows of the opposite side of the exit are dominant in cases of the Fig. 3 (a) and (b). However, in the Fig. 3 (c), flow of the opposite side of the exit is very week and flow at the corner beside of the exit is dominant. It indicates that the flow characteristics are quite different when the outlet position is changed.

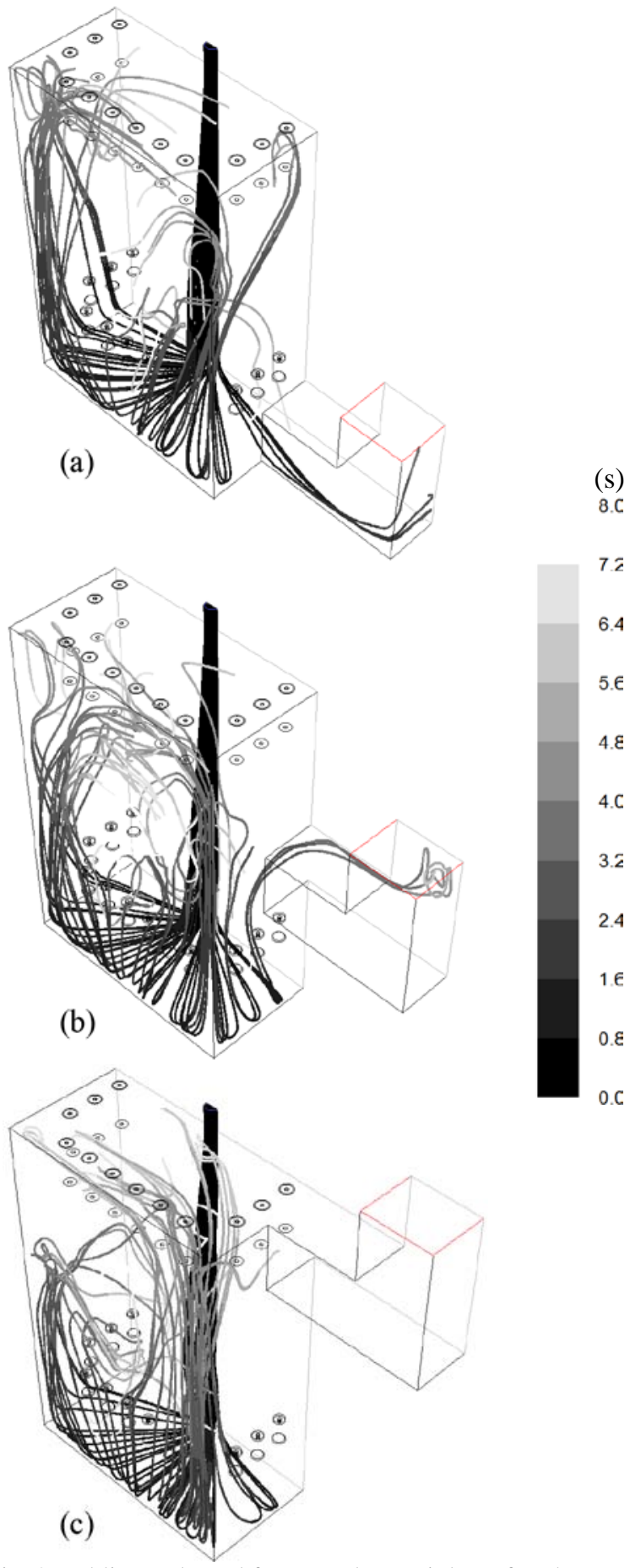

Fig. 3 Pathlines released from combustor inlets of each case

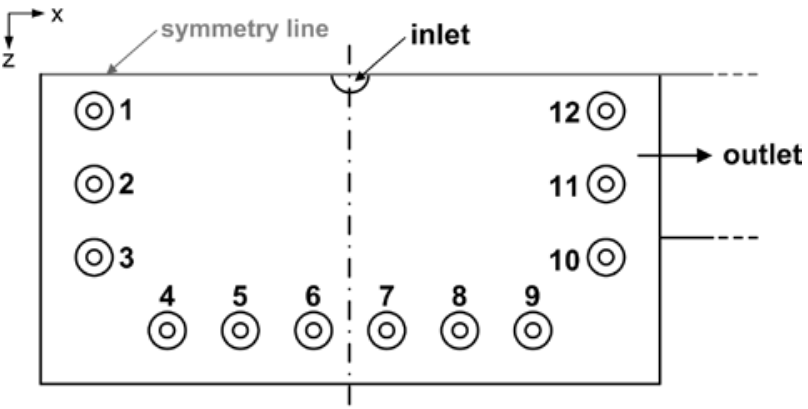

Fig. 4 A numbering method of reformer tubes

Since the flow in the combustion furnace is not uniform, reforming performance of each reformer tube might be different. From Fig. 5 to Fig. 7, outlet temperature, fuel consumption rate, and global hydrogen production rate of each reformer tube are shown, respectively. The global hydrogen production rate is defined as a ratio of generated hydrogen to supplied fuel. A numbering method of the reformer tubes is shown in Fig. 4.

As shown in Fig. 5, outlet temperatures of Case G1 and Case G2 are not uniform but, have similar trend. It reminds that the flows of Case G1 and Case G2 were similar. Fig. 5 also shows that outlet temperature of reformer 3 is highest in the case of Case G1 and G2. In their cases, flows of the opposite side of the exit which the reformer 3 is located were dominant. On the contrary, reformer 9 has the highest outlet temperature in Case G3.

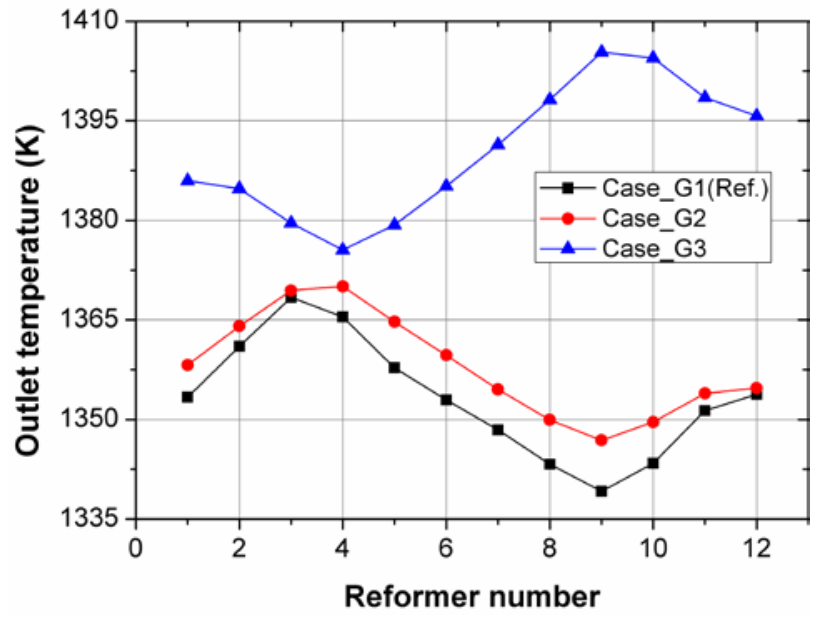

Fig. 5 Outlet temperatures of each reformer

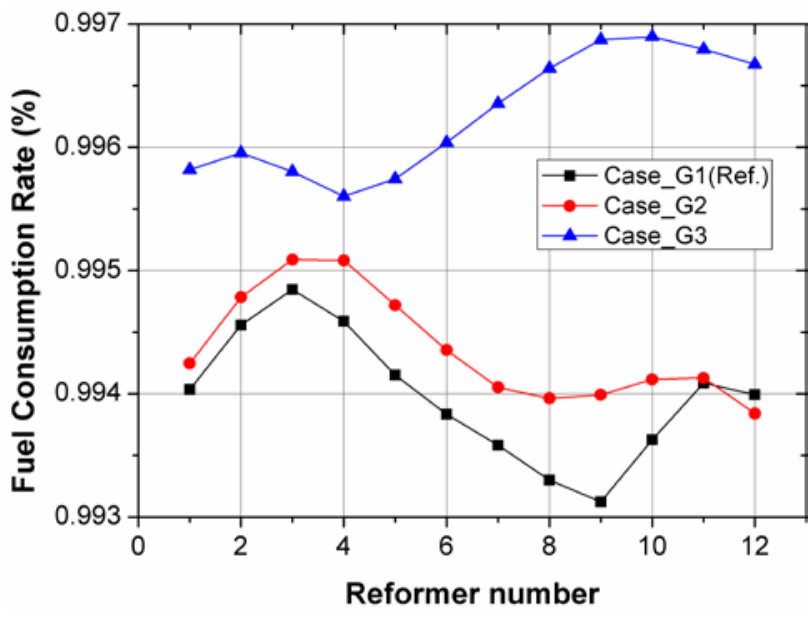

Fig. 6 Fuel consumption rate of each reformer 


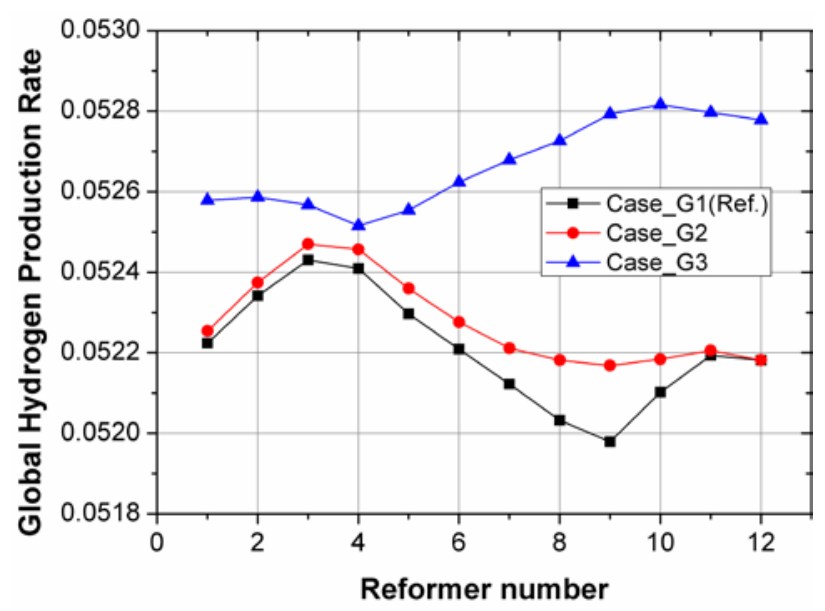

Fig. 7 Global hydrogen production rate of each reformer

In this case, the flow at the corner beside of the exit was dominant. It is concluded that outlet temperatures of reformers and flow characteristics have strong relation. It is shown that the trend in the Fig. 6 and 7 is very similar to that in the Fig. 5. This means that outlet temperature of reformer have strong relation with the fuel consumption and hydrogen production as well as flow characteristics. From these results, it is concluded that overall reformer performance and the flows in the combustion furnace can be predicted by measuring the outlet temperatures of reformer tubes. Although higher outlet temperature of reformers yields higher reformer performance and the outlet temperature of reformers of Case G3 is 2.5\% higher than that of Case G1, the fuel consumption rate and global hydrogen production rate of Case G3 are $1.0 \%$ and $0.2 \%$ higher than them of Case G1. This means that the effects of outlet position on the reformer performance is relatively lower than on the outlet temperatures of reformers.

\section{Conclusion}

A 250-kW fuel cell reformer was numerically simulated with a model using an appropriate user-defined function. The calculation domain was a simplified 3-D configuration. The numerical results were compared with experimental data for validation. To investigate the effects of geometries on flow characteristics and reforming performance, outlet position was changed from bottom to top of the combustion furnace.

The numerical results show that the flow characteristics are quite different when the outlet position is changed. And the flow characteristics in the combustion furnace strongly affect the outlet temperature of reformer and reforming performance. Overall, supplied fuel/air mixture goes down to the bottom of the combustion furnace and then spreads to the side wall of the furnace. This flow is relatively uniform. However, flows from the side wall are driven to the corner sides, and the reformers which are located around the corner sides have relatively higher outlet temperatures and better reformer performances.

The numerical results also show that outlet temperature of reformer have strong relation with the fuel consumption and hydrogen production as well as flow characteristics, thus overall reformer performance and the flows in the combustion furnace can be predicted by measuring the outlet temperatures of reformer tubes. The effects of outlet position on the reformer performance are relatively lower than on the outlet temperatures of reformers

\section{Acknowledgement}

This research was supported by the New and Renewable Energy Technologies Development Project of Korea Institute of Energy Technology Evaluation and Planning.

\section{References}

[1] S. Ahmed, R, Kumar, M, Krumplet, "Fuel processing for fuel cell power systems “, Fuel Cells Bull. 1999, Vol. 2, pp. 4-7.

[2] M. N. Pedenera, J. Pina, D. O. Borio, V. Bucala, "Use of a heterogeneous two-dimensional model to improve the primary steam reformer performance”, Chem. Eng. J. 2003, Vol. 94, pp. 29-40.

[3] M. de Jong, A. H. M. E. Reinders, J. B. W. Kok, G. Westendorp, "Optimizing a steam-methane reformer for hydrogen production”, Int. J. Hydrogen Energy 2009, Vol. 34, pp. 285-92.

[4] C. V. S. Murty, M. V. K. Murthy, "Modeling and simulation of a top-fired reformer", Ind. Eng. Chem. Res. 1988, Vol. 27, pp. 1832-40.

[5] J. Shayegan, M. M. Y. M. Hashemi, K. Vakhshouri, "Operation of an Industrial Steam Reformer Under Severe Condition: A Simulation Study”, Can. J. Chem. Eng. 2008, Vol. 86, pp. 747-55.

[6] G. Brus, J. Szmyd, "Numerical modelling of radiative heat transfer in an internal indirect reforming-type SOFC", J. Power Sources 2008, Vol. 181, pp. 8-16.

[7] Xu J, Froment GF. Methane steam reforming methanation and water-gas shift-I intrinsic kinetics. AIChE J 1989;35:88-96.

[8] Magnussen BF, Hjertager BH. On mathematical modeling of turbulent combustion with special emphasis on soot formation and combustion. P Combust Inst 1977;16(1):719-29.

\section{[9] FluentTM v6.3.26 User Guide.}

[10] NIST Chemistry WebBook. http://webbook.nist.gov/ chemistry/fluid/, Last access: Nov 15, 2012.

[11] Roses L, Manzolini G, Campanari S. CFD simulation of Pd-based membrane reformer when thermally coupled within a fuel cell micro-CHP system. Int $\mathrm{J}$ Hydrogen Energ 2010;35(22);12668-79.

[12] Steelss, http://www.steelss.com. Last access: Nov 15, 2012.

[13] Special Metals, http://www.specialmetals.com, Last access: Nov 15, 2012.

[14] MatWeb. http://www.matweb.com/search/ PropertySearch. aspx, Last access: Nov 15, 2012.

[15] Xu J, Froment GF. Methane steam reforming-II diffusional limitations and reactor simulation. AIChE J 1989;35:97-103. 